\title{
Children's poisoning profile during the Covid-19 pandemic - Experience of Hassan II University Hospital in Fez, MOROCCO
}

\author{
AMRANI HANCHI Sahar ${ }^{1,2}$, HOUMMANI Hasnae ${ }^{1,2}$, MOURABITI Hajar ${ }^{1,2}$, CHEBAIBI Mohammed $^{1,2}$, \\ CHAOUKI Sana ${ }^{3}$, ACHOUR Sanae ${ }^{1,2}$, TADMOURI Ilham ${ }^{3}$ and HIDA Moustapha ${ }^{3}$. \\ 1. Toxico-pharmacology department, CHU Hassan II, Fez, Morocco \\ 2. Biomedical and Translational Research Laboratory, Faculty of Medicine and Pharmacy, Sidi \\ Mohammed Ben Abdellah University, Fez, Morocco \\ 3. Pediatric Emergency Department G, CHU Hassan II, Fez, Morocco
}

\begin{abstract}
Introduction. - The Covid-19 pandemic and the containment situation, has generated enormous risks for children. Indeed, with the closure of schools, children, forced to stay at home, found themselves in permanent contact with dangerous products (drugs, disinfectants, plants) exposing them to accidental poisoning. Objective. - To describe the epidemiological, clinical and evolutionary aspects of the cases of pediatric intoxications in the UHC during the period of Covid19 , in order to assess the repercussions of this pandemic on the profile of these intoxications, in terms of number and incriminated products. Material and method. - This is a retrospective descriptive comparative study of intoxication cases admitted to the pediatric emergency department of the University Hospital of Fez spread over 2 years; from March 1, 2019 to February 2021; comparing intoxications admitted during the period of Covid-19 with the previous year. Results. The emergency department recorded 132 cases of intoxication during the Covid-19 period (compared to 104 cases in 2019). Fez was always the most concerned city (66.21\% against $69.02 \%$ in 2019). The cases emanated from the urban environment in (58.78\%). The accidental circumstance was the most frequent, with an increase from $77.88 \%$ in 2019 to $82.02 \%$. The rate of cases of envenomation that consulted was almost similar; children are more exposed to scorpion stings $(73.52 \%)$ than snake bites. The analysis of incriminated products was marked by the increase of Caustics (20.38\% in 2019 to $24.24 \%$ in 2020$)$, and the decrease of pesticides (19.41\% in 2019 to $13.63 \%$ ). The symptomatology was dominated by neurological signs in $25.75 \%$ of cases, followed by respiratory disorders $(18.18 \%)$. The evolution was favorable in $95.46 \%$, and death occurred in $4.54 \%$ of cases compared to $3.84 \%$ in 2019 . The Covid-19 pandemic has changed the use of antidotes.
\end{abstract}

\section{Introduction}

The emergence of the COVID-19 (Coronavirus Disease2019) pandemic has risen to be a significant global public health concern [1], that promoted a drastic and sudden change in the way we organize ourselves as social human beings. In March 2020, WHO declared that COVID-19 reached a pandemic status, putting the planet in a state of maximum alert and grew to dimensions that still cannot be measured today[2]. The literature has pointed out that older individuals are more susceptible to develop COVID-19, and those with major comorbidities such as diabetes, hypertension and obesity can be more affected and could potentially be at higher risk for severe illness and death [3]. Although youngsters appear to be less vulnerable to COVID-19, the side effects of the pandemic can be devastating [4]. In the context of the ongoing COVID-19 pandemic, most parents had to reorganize their lives to deal with working at home in addition to children's management, this sudden overload has been putting parents under extra stressful conditions, potentially increasing the risk of children face enormous dangers[5]. Indeed, with the closure of schools, children, forced to stay at home, found themselves in permanent contact with dangerous products (drugs, disinfectants, plants) exposing them to accidental poisoning. In fact, among children, the circumstances of intoxication are generally accidental and favoured by the deconditioning of the product and the non-respect of safety standards by some manufacturers [6]. This problem is aggravated by the presence of an informal market whose products are not subject to labelling or control of safety conditions [7]. More than $30 \%$ of intoxicated subjects in Morocco are children. More than 1000 deaths were recorded during the thirty years of the study, scorpionic envenomation, ingestions of toxic plants and the therapeutic errors are the most common cause of toxic deaths [8]. Moroccan studies in this field are rare, and the only study carried out by the CAPM on this subject was only interested in the characteristics of the intoxicated and the incriminated products. The present work will describe the epidemiological, clinical and evolutionary aspects of the cases of pediatric intoxications in the CHU Hassan II during the period of Covid-19, in order to assess the repercussions of this pandemic on the profile of these intoxications, in terms of number and incriminated products.

\section{Materials and methods}

* Corresponding author: sahar.amranihanchi@gmail.com 
It is a retrospective descriptive comparative study of intoxication cases occurred in children hospitalized at the pediatric emergency department of the Hassan II University Hospital of $\mathrm{Fez}$ during a period of 2-years; from $1^{\text {st }}$ March 2019 to February 2021; in order to compare the intoxications hospitalized during the period of Covid-19 with the previous year.

We included in this study, all types of intoxication, drugs, disinfectants, plants, pesticides etc. The data collection was realized by form of exploitation, to collect all the characteristics of the patient, the specificities of the intoxication (the place, the route, the circumstances, the product in cause). The clinical symptomatology presented by the patients was classified according to the classification of PSS; Poisoning Severity Score that grades the severity of the signs presented as (0) none, (1) minor, (2) moderate, (3) severe, and (4) fatal poisoning[9]. The evolution of the intoxicated person was also followed-up. All the collected data were tabulated in Excel ${ }^{\circledR}$ and analysed using the Epi software. A descriptive analysis of all variables was performed. Quantitative variables were expressed as mean, standard deviation, median and range. The qualitative variables as number and percentage.

\section{Results}

During the period of our study, the paediatric emergency department of the CHU Hassan II recorded 132 cases of intoxication during the Covid-19 period compared to 104 cases in 2019, with an augmentation of 28 cases during the Covid-19 period. These children were of urban origin in $79.65 \%(105 / 132)$; and emanated from the region of Fez-Meknes, Tanger-Tetouan-Al-Hoceima 0.96 (1/132) respectively. Fez was always the most concerned city (66.21\% against $69.02 \%$ in 2019 ) in the region of FezMeknes, as shown in Table 2.

The average age of our patients was $5.65 \pm 4.54$ years with extremes ranging from 2 months to 18 years, the sex ratio $(\mathrm{M} / \mathrm{F})$ was 0.95 in favor of a female predominance. In 2019, The average age was $5.70 \pm 5.07$ years with extremes ranging from 9 months to 18 years, the sex ratio $(\mathrm{M} / \mathrm{F})$ was 0.88 in favor of a male predominance. The most affected age group in Covid-19 era was 1 to 4 years in $51.51 \%$ of cases $(68 / 132)$, followed by 5 to 14 years in $0.40 \%$ of cases $(53 / 132)$. In 2019 , the distribution of age groups was almost similar; from 1 to $40.55 \%(58 / 104)$, followed by the age range from 5 to $1429.8 \%(31 / 104)$ Table 1.

Table 1. Age classification according to the INTOX system of the IPCS

\begin{tabular}{|c|c|c|}
\hline $\begin{array}{c}\text { Age } \\
\text { classification }\end{array}$ & 2019 & 2020 \\
\hline Baby & 58 & 68 \\
\hline Child & 31 & 53 \\
\hline
\end{tabular}

\begin{tabular}{|l|l|l|}
\hline Teenager & 15 & 11 \\
\hline
\end{tabular}

The Anti-Poison Center of Morocco (CAPM) uses this classification in order to meet international requirements, as it is based on the INTOX system in the registration of cases of intoxication that are reported to it. The classification of age groups according to INTOX, is interesting because it allows to classify the age groups according to following a logic of the circumstances of intoxication as well as the physical and mental development of the child. For example, the age range of the baby, between 1 and 5 years, is a period of acquisition of walking and of a great curiosity of the child which predisposes him to intoxications in the within the framework of the classic accident [8].

Table 2. Distribution of acute intoxications in children according to cities

\begin{tabular}{c|cccc} 
Cities & $\begin{array}{c}\text { Control } \\
\text { period } \\
2019\end{array}$ & $\%$ & $\begin{array}{c}\text { Study period } \\
2020\end{array}$ & $\%$ \\
\hline FEE & $\mathbf{7 2}$ & $\mathbf{6 9 . 2 0}$ & $\mathbf{8 6}$ & $\mathbf{6 5 . 1 5}$ \\
MEKNES & 2 & 1.92 & 4 & 3.03 \\
TAZA & 3 & 2.88 & 3 & 2.8 \\
Taounate & $\mathbf{1 8}$ & $\mathbf{1 7 . 3}$ & $\mathbf{1 8}$ & $\mathbf{1 3 . 7}$ \\
Other & $\mathbf{3}$ & 2.88 & 5 & 3.8 \\
Unknown & 6 & 5.76 & 26 & 19.69
\end{tabular}

The accidental circumstance was the most frequent, with an increase from $77.88 \%$ in 2019 to $87.12 \%(115 / 132)$ in the Covid-19 era. We noticed as well, a light diminution of the suicidal circumstance cases, from $(16.34 \%)$ of cases to $10.6 \%(14 / 132)$, observed mainly in Teenagers with extreme age range of 12 to 14 years. (Table 3)

The analysis of the route of intoxication showed that the oral route was predominant in both 2020 and 2019, followed by the dermal route, mainly related to scorpion stings and snake bites, as shown in table 6.

Table 3. Distribution of acute intoxications in children according to the circumstances of the intoxication

\begin{tabular}{r|llll}
\multicolumn{1}{c}{} & \multicolumn{3}{c}{ Control year } & \multicolumn{2}{c}{ Study period } \\
\cline { 2 - 5 } Accidental & 2019 & $\%$ & 2020 & $\%$ \\
Suicidal & 17 & 78.84 & 115 & 87.12 \\
Unknown & 5 & 16.34 & 14 & 10.60 \\
& & 4.8 & 3 & 2.27
\end{tabular}

The analysis of incriminated products was marked by the increase of Caustic products in the Covid-19 era from (20.38\% in 2019 to $24.24 \%$ in 2020$)$. The Caustic products were exclusively represented in the study by Petroleum distillate marking an increase from $23.8 \%$ in 2019 to $59.37 \%$ (19/32) in the Covid-19 era. With regard to caustics, household products were responsible for $28.12 \%(9 / 32)$ of cases of poisoning that were only due to the ingestion of hydrochloric acid and homemade bleach. The cases related to pesticides poisoning have shown a

* Corresponding author: sahar.amranihanchi@gmail.com 
slight decrease (19.41\% in 2019 to $13.63 \%)$. Otherwise, the drug poisoning cases were almost similar during the period of the study. A large variety of drug in cause.

Table 4. Main toxic classes responsible for acute intoxication in children

\begin{tabular}{lllll} 
& \multicolumn{2}{c}{ Control year } & \multicolumn{2}{l}{ Study year } \\
& 2019 & $\%$ & 20 & $\%$ \\
Drugs & & & 20 & \\
Antiepileptic drugs & $\mathbf{2 0}$ & $\mathbf{1 7 . 7}$ & $\mathbf{2 2}$ & $\mathbf{1 6 . 6 6}$ \\
Neuroleptic drugs & 4 & 38.8 & 7 & 31.68 \\
Antibiotic drugs & 3 & 16.7 & 4 & 18 \\
Antihistaminic drugs & 0 & 0 & 1 & 4.5 \\
Analgesic drugs & 3 & 16.6 & 1 & 4.5 \\
$\quad$ Antihypertensive & 1 & 5.55 & 0 & 0 \\
$\quad$ Unknown & 2 & 11.1 & 8 & 36.36 \\
Pesticides & $\mathbf{1 9}$ & $\mathbf{1 9 . 4}$ & $\mathbf{2 0}$ & $\mathbf{1 3 . 6}$ \\
Insecticide & 6 & 31.5 & 3 & 15 \\
$\quad$ Herbicide & 0 & 0 & 1 & 5 \\
Raticide & 7 & 36.8 & 8 & 40 \\
$\quad$ unknown & 6 & 31.5 & 8 & 40 \\
Plants & $\mathbf{6}$ & $\mathbf{5 . 7 6}$ & $\mathbf{5}$ & $\mathbf{3 . 7 8}$ \\
Animals & $\mathbf{2 2}$ & $\mathbf{2 1 . 1}$ & $\mathbf{3 5}$ & $\mathbf{2 6 . 5 1}$ \\
$\quad$ Scorpion & 19 & 86.3 & 25 & 71.42 \\
$\quad$ Snake & 3 & 13.6 & 10 & 28.57 \\
Caustics & $\mathbf{2 1}$ & $\mathbf{2 0 . 3}$ & $\mathbf{3 2}$ & $\mathbf{2 4 . 2 4}$ \\
Strong acid & & & & \\
Hydrochloric acid & 3 & 14.3 & 6 & 18.8 \\
Strong base & & & & \\
$\quad$ Bleach & 1 & 4.7 & 1 & 3.12 \\
Other & & & & \\
Petroleum distillate & 5 & 23.8 & 19 & 59.37 \\
Methanol & 0 & 0 & 1 & 3.12 \\
Disinfectant & 2 & 9.5 & 2 & 6.25 \\
Cosmetics & 1 & 4.7 & 0 & 0 \\
$\quad$ Vinegar + alcohol & 0 & 0 & 1 & 3.12 \\
Unknown & 9 & 42.5 & 2 & 6.25 \\
Food poisoning & $\mathbf{1}$ & $\mathbf{0 . 9 6}$ & $\mathbf{2}$ & $\mathbf{1 . 5 1}$ \\
Addictive drugs & $\mathbf{3}$ & $\mathbf{2 . 8 8}$ & $\mathbf{4}$ & $\mathbf{3 . 0 3}$ \\
Unknown & $\mathbf{9}$ & 8.56 & $\mathbf{1 1}$ & 8.33
\end{tabular}

The study of clinical characteristics during lockdown period showed that $76.04 \%$ of our patients were symptomatic. The most frequent symptoms were neurological signs in $26.51 \%$ of cases $(35 / 132)$. They were mainly dominated by unconsciousness in $(13.4 \%)$ of cases, drowsiness $(8.3 \%)$, agitation $(6.5 \%)$ and seizure in $(5.5 \%)$ of cases. Respiratory signs were present in second place in $25 \%$ of cases $(24 / 96)$; mainly tracheal stenosis, cough, respiratory distress, chest pain, bronchitis and dyspnea. Digestif signs were found in 9\% (8/89)of cases, including vomiting, diarrhoea, abdominal pain. Hematemesis related hospitalisation was due to ingestion of caustic product (Table 5). The analysis of the poisoning severity based on the PSS classification, shows the predominance of moderate and minor poisoning in both years of the study. Up to $15.16 \%$ of patients experienced Grade III severity issues with a significant increase from (8.6\% in 2019 to $15.16 \%$ in 2020$)$ requiring intensive care.

Table 5. The clinical signs presented by the patients.

\begin{tabular}{|c|c|c|}
\hline \multirow[t]{2}{*}{ Clinical signs } & $\begin{array}{c}\text { Control year } \\
2019\end{array}$ & $\begin{array}{c}\text { Study period } \\
2020\end{array}$ \\
\hline & $\%$ & $\%$ \\
\hline \multicolumn{3}{|l|}{ Neurological } \\
\hline$\checkmark \quad$ Drowsiness & 13.4 & 8.3 \\
\hline hypotonia & 5 & 4.6 \\
\hline
\end{tabular}

\begin{tabular}{|c|c|c|c|c|c|}
\hline$\checkmark$ & unconsciousness & 10 & 16.7 & 15 & 13.4 \\
\hline$\checkmark$ & agitation & 3 & 5 & 7 & 6.5 \\
\hline$\checkmark$ & seizures & 2 & 3.4 & 6 & 5.5 \\
\hline$\checkmark$ & $\begin{array}{l}\text { Status } \\
\text { epilepticus }\end{array}$ & 1 & 1.7 & 1 & 0.92 \\
\hline$\checkmark$ & $\begin{array}{l}\text { Muscarinic } \\
\text { syndrome }\end{array}$ & 1 & 1.7 & 1 & 0.92 \\
\hline$\checkmark$ & Cephalea & 0 & 0 & 1 & 0.92 \\
\hline$\checkmark$ & desoriotation & 0 & 0 & 2 & 1.9 \\
\hline$\checkmark$ & Hallusination & 0 & 0 & 1 & 0.92 \\
\hline$\checkmark$ & Vertige & 0 & 0 & 1 & 0.92 \\
\hline$\checkmark$ & Confusion & 0 & 0 & 1 & 0.92 \\
\hline$\checkmark$ & Coma & 0 & 0 & 1 & 0.92 \\
\hline \multicolumn{6}{|c|}{ Respiratory } \\
\hline$\checkmark$ & Tracheal stenosis & 2 & 3.4 & 1 & 0.92 \\
\hline$\checkmark$ & bronchitis & 2 & 3.4 & 4 & 3.7 \\
\hline$\checkmark$ & dyspnoea & 2 & 3.4 & 1 & 0.92 \\
\hline$\checkmark$ & Cough & 0 & 0 & 2 & 1.9 \\
\hline$\checkmark$ & $\begin{array}{l}\text { Respiratory } \\
\text { distress }\end{array}$ & 0 & 0 & 1 & 0.92 \\
\hline \multicolumn{6}{|c|}{ Digestif } \\
\hline$\checkmark$ & vomiting & 15 & 25 & 19 & 17.5 \\
\hline$\checkmark$ & diarrhea & 1 & 1.7 & 2 & 1.9 \\
\hline$\checkmark$ & Pain & 5 & 8.3 & 6 & 5.6 \\
\hline$\checkmark$ & HEMATEMESE & 0 & 0 & 1 & 0.92 \\
\hline \multicolumn{6}{|l|}{ ORL } \\
\hline$\checkmark$ & Ulcerations & 0 & 0 & 4 & 3.7 \\
\hline$\checkmark$ & Necrotic lesions & 0 & 0 & 3 & 2.8 \\
\hline \multicolumn{6}{|c|}{ Metabolic } \\
\hline$\checkmark$ & $\begin{array}{l}\text { Acidocétose } \\
\text { metabolic }\end{array}$ & 0 & 0 & 1 & 0.92 \\
\hline \multicolumn{6}{|l|}{ Renal } \\
\hline Renal f & ure & 0 & 0 & 1 & 0.92 \\
\hline \multicolumn{6}{|c|}{ Cardio vascular } \\
\hline$\checkmark$ & Bradycardia & 2 & 3.4 & 2 & 1.9 \\
\hline$\checkmark$ & tachycardia & 3 & 5 & 0 & 0 \\
\hline$\checkmark$ & hypotension & 2 & 3.4 & 1 & 0.92 \\
\hline$\checkmark$ & Chock & 0 & 0 & 1 & 0.92 \\
\hline \multicolumn{6}{|c|}{ Dermal } \\
\hline$\checkmark$ & Oedeme & 0 & 0 & 9 & 8.4 \\
\hline Total & & 60 & 100 & 108 & 100 \\
\hline
\end{tabular}

A symptom may be present in one or more patients.

Table 6. Main routes of poisoning in pediatric population.

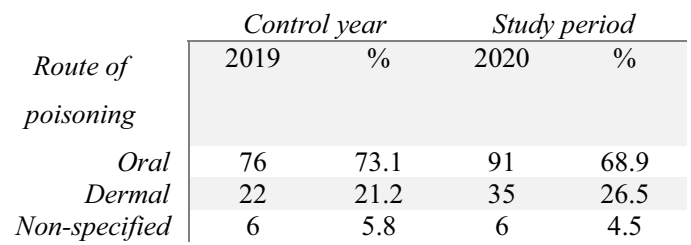

Table 7.1. Distribution of the evolution of the cases according to the studied parameters.

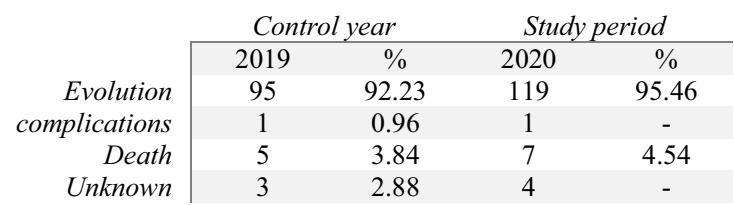


During the study period, 35 children were admitted for a scorpion sting and sanke bite. The medical records were analysed. As shown in table 4, The rate of cases of envenomation that consulted was almost similar in both years of the study; children are more exposed to scorpion stings $(73.52 \%)$ than snake bites, there have been 11 patients $(50 \%)$ within the grade II group and 1 patient (4.5\%) within the grade III group. The rest of the patients had moderate signs in 2019. In the Covid-19 period, we noticed that $20 \%$ of cases were hospitalized for grade II symptoms and a noticeable increase in patients with grade III symptoms $(11.35 \%)$, while the rest had moderate sings or have not presented no sings at all.

Snake and scorpion envenomation are more frequent within the summer; in fact, $91.7 \%$ of our patients were admitted between July and October.

Table 7.2 Comparison of paediatric emergency hospitalisations for poisonings cases, during the COVID-19 lockdown period and the corresponding period of the previous year.

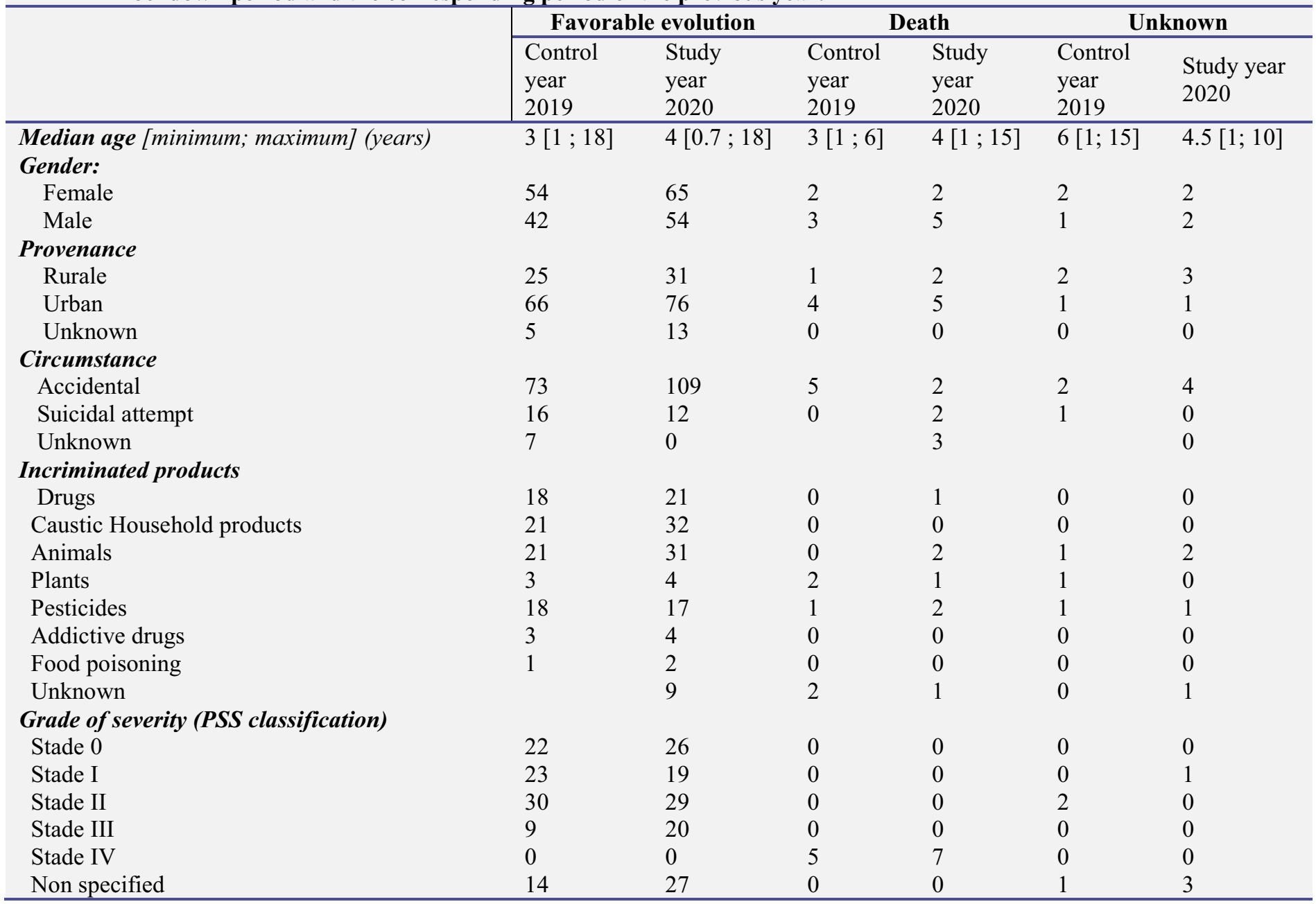

A detailed analysis of the envenomated cases in both years of the study showed the mean age of the children was $5.38 \pm 4.40$ years in $2019,(5.43 \pm 4.41$ in 2020$)$ with a male predominance as shown by the sex ratio $(\mathrm{M} / \mathrm{F}) ; 1.33$ in 2019 and (1.69 in 2020). These children emanated from the rural environment in the majority of the cases $(70 \%$ in $2019)$ and (94.2\% in 2020).

The envenomation was accidental in all cases. Death occurred in a 1-year-old child who accidentally got stung while being outdoors. The median time from poisoning to management was 4 hours with a minimum of half an hour and a maximum of 360 hours in 2019 , and 5.5 hours in 2020 with a minimum of 0.25 hour and 480 hours.

The evolution was favorable in $95.46 \%$, and death occurred in $4.54 \%$ of cases compared to $3.84 \%$ in 2019 .

\section{Discussion}

Long-term home isolation due to lockdown measures to prevent the spread of the COVID-19 outbreak bears the potential for increased risk of domestic accidents in children, as an additional collateral damage of this pandemic. $[10,11]$ Consequently, we intended to evaluate the impact of Covid-19 on poisoning cases in children in terms of recurrence (frequency) and severity between $1^{\text {st }}$ March, when lockdown measures were upheld in our country, and 28 February 2021 compared with the same corresponding period during the earlier year. We looked through the paediatric department (emergency and reanimation) electronic information base for cases identified with accidental or intentional poisonings. We

* Corresponding author: sahar.amranihanchi@gmail.com 
excluded children hospitalized for domestic accidents related to foreign bodies as well as any presentations flagged as a domestic injury. Our study showed that during lockdown period the frequency of poisoning cases in children has slightly increased. Intoxication varies from country to country and remains difficult to specify since, in most cases, it is a benign intoxication that does not even give rise to a medical consultation and thus escapes any statistical study[12]. In Morocco, between 16 March 2020 and 16 April 2020, the Moroccan Poison and Pharmacovigilance Center (CAPM) recorded 145 reports of poisoning cases in children, which represents $45.03 \%$ of all poisoning cases that occurred during the same period apart from scorpion stings and envenomation [13]. In our study, we collected 132 cases of poisoning in children, with an average of 11 cases per Month. In our series, the age group most concerned was between 1 and 4 years with a female predominance. These results are consistent with other published data in this area $[13,14]$. At this age, children tend to explore their immediate environment, it is also the age of walking acquisition where the hand-mouth activity is very important. Pesticides are involved in domestic accidents when they are left within reach of children due to negligence or accessible storage. When older children are involved, accidents often result from the misuse and the unpackaging of products. The oral route and the accidental circumstance are the most frequent and most reported characteristics of intoxication in all series [13, 15-18] [17] Indeed, deconditioning and failure to follow safety standards seem to be the main cause of accidental ingestion cases in children in our setting. In our study, the main incriminated products were caustic products dominated in $24.24 \%$ of cases, petroleum distillate, bleach and household products are the leading cause of caustic poisoning among children. However, the Covid-19 period has seen the recording of a case of poisoning by a new type of mixture (vinegar +white spirit) (absent in 2019). Petroleum distillate is a Moroccan specificity in our study, it was responsible for 19 cases of ingestion. It has been widely used in most Moroccan households as a disinfectant for surfaces and air, in order to reduce the propagation of the virus, this would be the cause of accidental ingestion in children, especially during the application of these products for viricidal purposes. The appearance of cases of intoxication by mixtures of disinfectants was also recorded by the Moroccan Poison Control and Pharmacovigilance Center (CAPM), this practice was observed during the Covid-19 health crisis and is wrongly assumed to increase the virucidal effectiveness of the disinfectants used. The use of disinfectant mixtures seems to expose to an increased risk of poisoning mainly in children [13]. Drugs represent $16.66 \%$ of cases, pesticides have known a decrease from (19.41\% in 2019 to $13.63 \%$ ). According to data from the Moroccan Poison Control and Pharmacovigilance Center (CAPM) [13], The analysis of products incriminated in intoxications in 2020 showed that drugs were in the lead $(55.16 \%)$ followed by disinfectants $(14.40 \%)$ and pesticides and agricultural products while in 2019, drugs were in the lead $(45 \%)$ followed by pesticides and agricultural products (10.36\%) and disinfectants (8.04\%).
According to Moroccan series, the clinical manifestations are essentially respiratory, neurological and followed by digestive signs, which is consistent with the results recorded in our study $[1,13]$. The immediate complications are often limited and related to the substance in cause. Among children, the exposure to toxic agents is not always accidental. In our series, voluntary intoxications involve children over 10 years of age, mainly females. These suicide attempts are related to the ingestion of various drugs or pesticides available to their reach. According to a paediatric study, $19 \%$ of organophosphate intoxications were voluntary [19]. In our study, the main toxic agents involved were, organophosphates, aluminium phosphate and alpha chloralose. The suicidal attempt has significantly decreased, which is not consistent with the data from CAPM and international studies [13, 20]. Poisoning in children during the Covid-19 pandemic is fatal. In our study, the rate of death has increased from $3.84 \%$ in 2019 of cases compared to $4.54 \%$ in the same period in 2020 , this can be related to the increase in the delay between the intoxication and management, due to the fear of population to be infected by the SARS-Cov virus. A detailed analysis of death cases reveals that the median age of these children was $4[1 ; 15]$ with a sex ratio of 2.5 with a male predominance. The distribution of deaths according to the circumstance showed that the accidental circumstance was responsible for 2 deaths among 7 cases (28.6\%); related to scorpion sting, and 2 cases among 7 in suicidal attempts $(28.6 \%)$, The main toxic agents in cause were related to pesticides, represented exclusively by aluminium phosphide. Indeed, Aluminium phosphide is used in Morocco as a fumigant to control rodents and pests in grain-storage facilities [21]. The trade name of the fumigant is Phostoxin $\AA$. Aluminium phosphide is highly toxic, low cost and easily accessible. This explains why it is the main cause of poisoning in our study. Patients who intend to commit suicide take tablets. Once mixed with aqueous solutions in the stomach, phosphine gas (PH3) is released [22]. The release of cytotoxic phosphine gas primarily affects the heart, lungs, gastrointestinal tract and kidneys, although all organs can be involved. Only 1 death case by plant poisoning was recorded, while in 2019 2 cases of death were related to poisoning by plant (Chenopodium ambrisoide) has been recorded. In fact, this plant is widely used in traditional Moroccan remedies especially among children, as an antipyretic, vermifuge, antispasmodic, or for its healing effect in oral ulcerations [23]. However, the misuse of this plant in traditional remedies is responsible for many cases of intoxication, which would be related to an overdose, since the toxic dose is very close to the therapeutic dose. The most important bioactive compounds in the aqueous extract and essential oil of the plant are p-cymene $(50.0 \%)$, terpinene $(37.6 \%)$ and ascaridol (3.5\%). The toxicity of the plant is due to the three active ingredients mentioned, as they are responsible for the inhibition of the complex I of the mitochondrial respiratory chain leading to a multivisceral lesions that starts with digestive disorders (vomiting, diarrhea) and reaches the neurological system (CNS depression, headaches, convulsions, coma), neurosensory disorders (deafness, visual impairment) and can be

*Corresponding author: sahar.amranihanchi@gmail.com 
complicated by cardiovascular, hepatic and renal signs [24] which is consistent with the data of our study.

\section{Conclusion}

The Covid-19 health crisis and the sanitary lockdown situation had an impact on the profile of children's poisoning in PED. An increase in cases of caustic poisoning, the use of disinfectant mixtures, and the appearance of new poisoning circumstances. Even though, There is limited data regarding the epidemiologic characteristics and clinical features of SARS-CoV-2 in children [25]. We acknowledge our data are limited by the single-centre design, with the possibility that little variations in numbers in each period could influence the impact size of our results. However, we acknowledge they are valuable and useful to raise awareness that domestic accidents are posing a higher danger to children's wellbeing and health than COVID-19, as well as to gain a better comprehension of the global effect of COVID-19 on the paediatric population.

\section{References}

1. Jing, J.L.J., et al., Hand sanitizers: a review on formulation aspects, adverse effects, and regulations. International journal of environmental research and public health, 2020. 17(9): p. 3326.

2. Organization, W.H., WHO characterizes COVID-19 as a pandemic. World Health Organization, 2020.

3. de Figueiredo, C.S., et al., COVID-19 pandemic impact on children and adolescents' mental health: Biological, environmental, and social factors. Progress in Neuro-

Psychopharmacology and Biological Psychiatry, 2021. 106: p. 110171.

4. Spinelli, M., et al., Parents' stress and children's psychological problems in families facing the COVID-19 outbreak in Italy. Frontiers in Psychology, 2020. 11: p. 1713.

5. Crescentini, C., et al., Stuck outside and inside: an exploratory study on the effects of the COVID-19 outbreak on Italian parents and Children's internalizing symptoms. Frontiers in psychology, 2020. 11.

6. JALAL, G., et al., Intoxication par les produits caustiques. Espérance médicale, 2004. 11(111): p. $578-582$.

7. Iken, I., et al., Les intoxications par les produits d'entretien ménagers caustiques et irritants en milieu pédiatrique: expérience du CHU Hassan II de Fès entre 2008 et 2014. Toxicologie Analytique et Clinique, 2017. 29(2): p. 234240.

8. Dr Naima Rhalem, M.R.A., Les intoxications aiguës chez l'enfant. 2012.

9. Hans E. Persson, G.K.S., John A. Haines \&Jenny Pronczuk de Garbino, Poisoning Severity Score. Grading of Acute Poisoning.
Journal of Toxicology: Clinical Toxicology, 2009.

10. Lazzerini, M., et al., Delayed access or provision of care in Italy resulting from fear of COVID-19. The Lancet Child \& Adolescent Health, 2020. 4(5): p. e10-e11.

11. Viner, R.M., et al., School closure and management practices during coronavirus outbreaks including COVID-19: a rapid systematic review. The Lancet Child \& Adolescent Health, 2020. 4(5): p. 397-404.

12. Jalal, G., et al., Intoxications par les produits d'entretien ménager au Maroc. Données du Centre anti-poison du Maroc (1980-2008). Toxicol Maroc, 2011. 10.

13. Rachida Soulaymani Bencheikh, H.C., Le Centre Antiopoison et de la Pharmacovigilance du Maroc face à la pandémine du Covid-19, in Revue de toxicologie

14. Scholz, K.-A., COVID and kids: Lockdowns have harmed children's health. 2021.

15. ANSES, C.A.F., COVID-19 : attention aux intoxications liées à la désinfection et aux autres situations à risque.

16. ANSES, C.A.F., Covid-19 et toxicovigilance 2020.

17. UK, U., CHILDREN IN LOCKDOWN: WHAT CORONAVIRUS MEANS FOR UK CHILDREN. 2020.

18. Bresson, A., COVID-19: hausse des accidents domestiques liés à une intoxication, alertent les Centres antipoison. 2020.

19. Bichri S, D.G., Sakhi A, et al, Intoxications aiguës aux organophosphorés chez l'enfant. Ann Toxicol Anal 2006;18:223-57., 2006.

20. Hoekstra, P.J., Suicidality in children and adolescents: lessons to be learned from the COVID-19 crisis. European Child \&

Adolescent Psychiatry (2020) 29:737-738, 2020.

21. Hajouji Idrissi M, O.L., Abidi K, Abouqal R, and Z.A. Kerkeb O, Severity factors of aluminium phosphide poisoning (Phostoxin). Ann $\mathrm{Fr}$ Anesth Reanim 2006;25:382-5. .

22. Chugh SN, K.T., Kakkar R, Chugh K, Sharma $\mathrm{S}$, . A critical evaluation of anti-peroxidant effect

of intravenous magnesium in acute aluminum phosphide poisoning. Magnes Res 1997;10:22530.

23. Jardim CM, J.G., Dhingra OD, Freire MM. , Composition andantifungal activity of the essential oil of the Brazilian Chenopodium ambrosioides L. J Chem Ecol. 2008; 34:1213 8.

24. Monzote L, S.W., Staniek K, Lars G. , Toxic effects of car-vacrol, caryophyllene oxide and ascaridole from essential oil of Chenopodium ambrosioides on mitochondria. . Toxicol AppliedPharmacol, 2009: p.;240:337-47.

25. Lu, X., et al., SARS-CoV-2 infection in children. New England Journal of Medicine, 2020. 382(17): p. 1663-1665.

* Corresponding author: sahar.amranihanchi@gmail.com 